\title{
SOCIEDADE DE RISCO, SUSTENTABILIDADE PARA GESTÃO E PRINCÍPIO DA PRECAUÇÃO ${ }^{1}$
}

\author{
RISK SOCIETY, SUSTAINABILITY FOR MANAGEMENT AND \\ THE PRECAUTIONARY PRINCIPLE
}

\author{
Magno Federici Gomes ${ }^{2}$ \\ Leonardo Paiva de Mesquita ${ }^{2}$
}

Recebido em: 19/07/ 2016 Aceito em: 22/12/2016

federici@pucminas.br leomesq@hotmail.com

\begin{abstract}
Resumo: O presente artigo analisou a sociedade industrial de risco e os riscos que ela mesma produz. Por conseguinte, o surgimento do princípio da precaução no contexto de incertezas e avanço da degradação ambiental, sua utilização no direito nacional e estrangeiro, bem como a análise do elemento da incerteza científica. A metodologia utilizada foi a jurídico-teórica e o procedimento de raciocínio o dedutivo, com técnica de pesquisa bibliográfica. Por fim, concluiu-se pela necessidade de ultrapassar vários argumentos privatistas de ordem econômica e social para, diante do risco, resguardar a proteção ao meio ambiente, através do uso do princípio da precaução.
\end{abstract}

Palavras-chave: Sociedade de risco. Incerteza científica. Risco de dano. Princípio da precaução. Instrumento de gestão.

\begin{abstract}
This paper analyzed the industrial society of risk and the risk that she produces. Therefore, the emergence of the precautionary principle in the context of uncertainty and advancement of environmental degradation, then its use in comparative law and the analysis of the scientific uncertainty element. It fell also demonstrate the devices introduced the precautionary principle in Brazilian law and its application by the judiciary. Finally, it was concluded by the need to overcome a number of arguments for economic and social order, with the risk, safeguard the protection of the environment through the use of the precautionary principle.
\end{abstract}

Keywords: Risk Society. Scientific Uncertainty. Damage Risk. Precautionary Principle. Management Tool.

\section{INTRODUÇÃO}

O direito ambiental busca várias formas de tutelar o meio ambiente face às diversas formas de degradação das atividades antrópicas. Isto porque o desenvolvimento humano, o progresso e o alargamento das atividades econômicas são fatos hodiernos inevitáveis e sem volta.

Porém, a incessante corrida por superação do já conquistado e a subjugação de tudo, inclusive do meio ambiente, na perspectiva de Beck (2011) torna o atual modo de vida insustentável por períodos longos, característica difícil de ser vencida numa geração marcada pelo imediatismo. A Constituição da República de 1988 (CR/1988) assegura a livre iniciativa econômica e sabe-se que é necessário o fomento das atividades econômicas para desenvolvimento do país. Porém, o que se propõe neste artigo é refletir sobre qual desenvolvimento a atual geração está disposta a construir.

O objetivo do artigo é analisar o princípio da precaução no Brasil e em outros países. Muito mais do que pensar instantaneamente, deve-se buscar além do horizonte uma nova forma de desenvolvimento que seja sustentável não apenas para um determinado país ou geração.

\footnotetext{
${ }^{1}$ Financiamento e Grupo de Pesquisa (CNPQ).

${ }^{2}$ Escola Superior Dom Helder Câmara - Belo Horizonte - Minas Gerais - Brasil
} 
E como os poderes econômicos não se predem às fronteiras traçadas pelas ficções políticas, na perspectiva de Leff $(2010 ; 2012)$, assim como os impactos ambientais não conhecem os limites que separam as nações constituídas e porque se perpetuam por várias gerações, mister se faz redesenhar novas formas para uma gestão sustentável.

O princípio da precaução pode limitar a atividade desenfreada do nodo de vida capitalista/consumista, mas por óbvio recebe grandes críticas na forma de seu uso.

Entender o contexto histórico pelo qual se passou, para tentar compreender o atual cenário será importantíssimo para uma reflexão mais profunda do que se deseja construir para o futuro.

Compreender o contexto de uma época, inserida nela, é uma tarefa difícil, inglória e cheia de espinhos, principalmente pelas fáceis críticas que se levantam. Todavia, os primeiros passos devem ser iniciados para que se possa construir uma jornada duradoura.

Os riscos dessa tentativa, assim como da própria existência, não podem ser justificativa para permanecer inertes ao que acontece, principalmente diante da maior degradação ambiental desferida nos últimos séculos.

Os riscos criados e suportados chegam ao seu extremo sob a égide de um direito que garante primordialmente a liberdade e a propriedade, mas que não efetiva uma igualdade de condições e justa distribuição de condições.

Para lidar com esta conjuntura, sem negar as garantias arduamente conquistadas, mas também sem deturpá-las no seu uso extremado, capaz de gerar mais injustiças do que realmente a tão sonhada justiça, se faz necessário criar novas instrumentos capazes de lidar com gestão sustentável e assim o princípio da precaução pode se firmar como um novo remédio para os novos males desse tempo.

A metodologia utilizada foi a jurídico-teórica e o procedimento de raciocínio o lógico dedutivo. A técnica usada foi a de pesquisa bibliográfica.

\section{SOCIEDADE DE RISCO}

Durante muitos séculos, os homens em suas sociedades organizadas lutavam contra a fome, eventos naturais e epidemias. Porém, com o advento da modernidade e da Revolução Industrial, vários destes problemas foram superados. Por outro lado, com o avanço tecnológico da Idade Contemporânea e o crescimento populacional, intensificaram-se as ações antrópicas sobre a natureza.

Beck (2011) demonstra que no século XIX, a sociedade que se opunha à natureza com o propósito de controlá-la, no final do século XX realmente já a tinha subjugada e superexplorada (BECK, 2011, p. 9).

Nessa conjuntura de abundância material, de uma boa parcela da população mundial, o que se questiona na pós-modernidade é pauperização da civilização, daquela sociedade industrializada clássica, que rompera com a modernidade e assume nova forma, denominada de "sociedade 
(industrial) de risco". Nesta sociedade, sequer é possível saber se chá contém DDT ${ }^{3}$ ou se a cozinha tem formaldeído, dessa forma, questiona Beck (2011):

Se hoje for comprovado de forma social vinculante que o formaldeído, DDT etc., nas suas concentrações em que essas substâncias químicas são encontradas nos objetos de uso cotidiano e nos alimentos, têm efeitos danosos à saúde, essa constatação seria equivalente a uma catástrofe, pois elas estão presentes em toda parte.

Isto torna claro que, o potencial de ameaça das forças produtivas a margem de manobra para a pesquisa científica torna-se cada vez mais estreita. Hoje em dia, admitir que se cometeu um erro na estipulação de tetos para a tolerância de pesticidas - o que, no fundo, é o que normalmente acontece na ciência -, equivale ao desencadeamento de uma catástrofe política (ou econômica), devendo por isso mesmo ser evitada (BECK, 2011, p. 65).

E destarte é que se desenvolve ao máximo a latência das ameaças que cercam, ao ponto de tornarem visíveis como os processos de desertificação em antigas áreas de vegetação, poluição das águas, catástrofes causadas por materiais tóxicos, sendo que para estes casos existem uma maior comoção social e cobertura da imprensa. Por conseguinte, os riscos já fazem parte da consciência pública e por isso tornam-se um fator político.

Os riscos são cientificados e ao mesmo tempo são comercializados. Se a fome pode ser superada em boa parte do mundo, mas não nele todo, os riscos se tornam um novo produto, um "saco sem fundo", que não pode ser exaurido e nem aplacado. Leia-se:

Mas o que conta decisivamente em favor disso é uma sintomática e simbólica 'superação' do risco. Os riscos precisam aumentar com sua superação. Na verdade, não devem ser superados em suas causas, em suas fontes. Tudo acontece no âmbito da cosmética do risco: embalagem, mitigações sintomáticas da poluição, instalação de filtros purificadores ao mesmo tempo em que se mantêm as fontes poluidoras. Ou seja, nada preventivo, mas apenas uma indústria e uma política simbólicas de superação da multiplicação dos riscos (BECK, 2011, p. 68).

A sociedade industrial baseada sob os riscos que ela mesma produz gera situações de ameaça social, política e econômica, devendo-se questionar os fundamentos dessa "evolução" a qual vem trilhando. Segundo Beck (2011):

As ciências, portanto, da maneira como estão constituídas - em sua ultraespecializada divisão do trabalho, em sua compreensão de métodos e teorias, em sua heterônoma abstinência da práxis -, não estão em condições de reagir adequadamente aos riscos civilizacionais, de vez que têm destacado envolvimento em seu surgimento e expansão (BECK, 2011, p. 71).

\footnotetext{
${ }^{3} \mathrm{O}$ diclorodifeniltricloroetano, cuja sigla é DDT, trata-se de um pesticida moderno largamente usado pós segunda guerra. Por ser barato e altamente eficaz no combate de mosquitos vetores de doenças como malária e dengue usado em vários países. Porém após o diversos estudos, dentre eles, o desenvolvido pela bióloga Rachel Carson no livro Primavera Silenciosa, demonstra que o uso do DDT pode ocasionar câncer em seres humanos e aumento da mortalidade dos pássaros dentre outras interferências na vida animal. Na década de 1970 muitos países aboliram seu uso foi rigidamente controlado pela Convenção de Estocolmo dobre Poluentes Orgânicos Persistentes (SALLUM, 2012, internet).
}

Revista do Direito [ISSN 1982-9957]. Santa Cruz do Sul, v. 3, n. 50, p. 16-33, set./dez. 2016. https://online.unisc.br/seer/index.php/direito/index 
Perante essa realidade e da profunda profissionalização sistêmica, em que todos são especializados em suas atividades, "mas ninguém é competente para lidar com os riscos da modernização" (BECK, 2011, p. 74), se entende como é fácil trapacear cientificamente em uma racionalidade social na consideração dos riscos. Assim:

O reverso da natureza socializada é a socialização dos danos à natureza, sua transformação em ameaças sociais, econômicas e políticas sistêmicas da sociedade mundial altamente industrializada. $\mathrm{Na}$ globalidade da contaminação e nas cadeias mundiais de alimento e produtos, as ameaças à vida na cultura industrial passam por metamorfoses sociais do perigo: regras da vida cotidiana são viradas de cabeça para baixo. Mercados colapsam. Prevalece a carência em meio à abundância. Caudais e demandas são desencadeados. Sistemas jurídicos não dão conta das situações e fato. As questões mais prementes causam desdém. Cuidados médicos falham. Edifícios de racionalidade científica ruem. Governos tombam. Eleitores indecisos fogem. E tudo isso sem que a suscetibilidade das pessoas tenha qualquer coisa que ver com suas ações, ou suas ofensas com suas realizações e ao mesmo tempo em que a realidade segue inalterada diante e nossos sentidos (BECK, 2011, p. 10).

Existem hoje os perigos já conhecidos e evidentes que são objeto de restrição do Poder Público, mas por outro lado, como se vê, ainda existem os riscos que não são dedutíveis, não são comprovados cientificamente. E diante desta realidade oculta, não se pode esperar, sob pena de ser tarde demais. Logo, o princípio da precaução busca evitar que os acidentes se transformem em verdadeiras catástrofes.

\section{CONSIDERAÇÕES SOBRE O PRINCÍPIO DE PRECAUÇÃO}

Neste capítulo será trabalhado a necessidade de se compreender uma sociedade pósmoderna, constituída de diferentes matizes, com conhecimentos e saberes oriundos de outras tradições que não se enquadram na técnica cientificista ocidental, que se baseia primordialmente numa sociedade de consumo onde tudo é transformado em produto/valor. A lógica liberal/capitalista que observa apenas a propriedade não é mais capaz de resolver questões complexas do ambiente a sua volta, que está a ponto de um colapso, e sua evolução se torna necessária.

Desde a década de 70 o princípio da precaução (vorsorgeprinzip) se encontra presente no Direito alemão, conforme Sampaio (2003, p.58-59). Sua origem no âmbito internacional pode ser verificada na Carta Mundial da Natureza editada pela Resolução 37/7 da Organização das Nações Unidas (ONU), de 1982. Exatamente uma década depois, em 1992, na convenção da ONU, realizada no Rio e Janeiro, elaborou-se a Declaração do Rio sobre Ambiente e Desenvolvimento, que em seu art. 15 consta expressamente tal princípio. Nesta mesma convenção, outro documento, sobre Mudança do Clima, introduziu a precaução em seu art. $3^{\circ}$.

O princípio da precaução busca antever a existência do risco com sua probabilidade de dano ao meio ambiente ecologicamente equilibrado. Na certeza científica do dano, a atividade deve ser 
afastada e aplicado o princípio da prevenção. Já quando não há unanimidade da incerteza o dano, o princípio da precaução entra em cena.

Existe uma complexidade do conhecimento que não pode ser confundida com uma generalizada relativização e um ecletismo epistemológico, "mas o encontro de tradições e formas de conhecimento legitimadas por diferentes matrizes de racionalidade, por saberes arraigados em identidades próprias que não só entram em jogo num processo de tomada de decisões, mas que 'se hibridam"' (LEFF, 2010, p. 180) diante da globalização marcada pela valorização mercantil frente a conservação ecológica e os diversos significados culturais.

E não é demais usar os ensinamentos de Leff (2012) sobre a racionalidade ambiental e sua complexidade, que não está pronta, mas busca no horizonte, no ainda não pensado, através também de saberes colocados à margem de práticas tradicionais, e processos de produção de atores urbanos, camponeses e indígenas, que abre um diálogo entre saberes tradicionais e modernos:

A racionalidade ambiental desponta no horizonte da sustentabilidade como
condição de vida: não apenas da biodiversidade, mas da vida humana, da
cultura, do sentido da existência. É uma nova compreensão o mundo que
habitamos. Nesta fronteira que marca a transição entre a modernidade e
pós-modernidade se questiona a racionalidade que sustentou o mundo
moderno e se vislumbra uma nova racionalidade. Esta revisão das
categorias do pensamento não é um simples refluxo de ideias nas marés do
conhecimento. Não é o reflexo de uma realidade complexa no pensamento
da complexidade. [...] O pensamento novo é ruptura, mas não faz tábula
rasa do pensamento que o antecede; não decapita o conhecimento
científico; não esquece os saberes tradicionais (LEFF, 2012, p. 129-130).

Neste sentido o incerto não pode ser descartado. Apesar de ainda não estar bem definido, pesado e medido, deve ser objeto de pesquisa. O jurista Lavieille, citado por Machado (2015), expõe que "o princípio da precaução consiste em dizer que não somente somos responsáveis sobre o que nós sabemos, sobre o que nós deveríamos ter sabido, mas, também, sobre o de que nós deveríamos duvidar" (LAVIEILLE apud MACHADO, 2015, p. 102). A seguir, o conhecimento somente aflorará quando dedicado empenho e trabalho para solução e sua hipótese. Leia-se:

A certeza equivale à ausência de dúvidas e de imprecisão. O estado de certeza tem por objetivo dar-nos segurança, sendo que a incerteza gera insegurança. Diante da incerteza do dano ambiental, não se pode ficar derrotado pela inércia e pela omissão. A procura da informação sobre a incerteza é um dos motivos de se apelar para a aplicação do princípio da precaução (MACHADO, 2015, p. 102).

Não se pode impedir um empreendimento diante da busca de certeza de ausência de danos, pois assim estar-se-ia buscando o "risco zero", o que não é possível na sociedade de risco. Assim, o que existe, são os riscos toleráveis (cuja lesão é improvável ou os benefícios da atividade são maiores, que os danos se tornam de menor importância) e os intoleráveis, que são os riscos objeto de limitação, e serão impedidos através do princípio da precaução (BECHARA, 2009, p. 30-31)

Por fim, o princípio da precaução, segundo Canotilho e Leite (2008), assume a conotação de princípio "in dúbio pro ambiente", explicando que no caso de dúvida se a atividade causa dano ao meio 
ambiente, deve-se decidir à favor da preservação ambiental e contra o potencial poluidor. Acrescenta ainda que "quando ainda não se verificarem quaisquer danos decorrentes de uma determinada actividade, mas se receia, apesar a falta de provas científicas, que possam vir a ocorrer" o princípio da prevenção deve ser aplicado (CANOTILHO; LEITE, 2008, p. 42).

Diante da sociedade (de risco) industrializada e globalizada, na qual a latência das ameaças é aprofundada ao máximo e não se tem o pleno conhecimento dos riscos aos quais se está exposto, é importante destacar que seus efeitos são transfronteiriços:

Além de gerarem efeitos transfronteiriços, os riscos não se esgotam, contudo, em efeitos e danos já ocorridos, pois exprimem, sobretudo, um componente futuro, na extensão futura dos danos atualmente previsíveis e em parte numa perda geral de confiança ou num suposto "amplificador de riscos". O risco, portanto, além de produzir efeitos globais (transfronteiriços), também produz efeitos atemporais, sendo que as ameaças podem não ser visíveis e perceptíveis à presente geração, porém poderão o ser às gerações futuras (PELLANDA, 2013, p. 98).

E a partir deste contexto, Leff (2012) defende que a crise ambiental é uma crise de conhecimento, questionando a racionalidade e os paradigmas teóricos que impulsionaram o desenvolvimento, questionando sem dúvida as próprias bases de produção. Segundo o autor (2012):

A crise ambiental é uma crise do conhecimento. O saber ambiental que dali emerge como a invasão silenciosa de saber negado se infiltra entre as muralhas defensivas do conhecimento moderno; se filtra entre as malhas teóricas através de suas estratégias discursivas. A epistemologia ambiental derruba os muros de contenção da ciência e transcende todo conhecimento que se converte num sistema de pensamento. Desse modo, chega a questionar o marxismo e o estruturalismo, mas ao mesmo tempo usa suas armaduras teóricas contra o projeto positivista (universalista, coisificador, reificante) do conhecimento. O saber ambiental desvela e desentranha as estratégias de poder que se entremeiam na epistemologia empirista e racionalista que confundem o ser com o ente, o real com a realidade, o objeto empírico e o objeto de conhecimento; desmascara as estratégias conceituais das teorias de sistemas e do pensamento ecológico; estabelece as bases epistemológicas para a articulação teórica das ciências e abre conhecimento para um diálogo dos saberes (LEFF, 2012, p. 19-20).

Diante disto é que a sustentabilidade ecológica emerge como forma de estruturar o modo de vida e produção da sociedade. E para isso, é necessário criar instrumentos de controle dos poderes que operam na lógica dominante.

A partir dessas premissas, o uso da precaução repelirá todo argumento de dúvida que subsidia a degradação ambiental descomedida e em sentido contrário impelirá a adoção de medidas mais eficazes para fortalecimento da proteção ao meio ambiente.

\subsection{Do direito estrangeiro}

Revista do Direito [ISSN 1982-9957]. Santa Cruz do Sul, v. 3, n. 50, p. 16-33, set./dez. 2016. https://online.unisc.br/seer/index.php/direito/index 
O princípio da precaução é considerado um dos mais importantes princípios do direito ambiental. A influência do "vorsorgeprinzip", lá do direito alemão, provavelmente influenciou a regra de cautela, existente no art. 174 da versão consolidada do Tratado da União Europeia (MACHADO, 2015, p. 95). Segundo este princípio, a inexistência de certeza científica plena sobre os possíveis efeitos nocivos que pode produzir um determinado fenômeno não exime da adoção de precauções que a prudência recomenda (ÁNGEL YÁGÜEZ, 2008, p. 99).

Na Alemanha, o cerne do conceito da precaução é "dar às autoridades certa margem de apreciação para decidir se determinada medida de proteção ambiental é verdadeiramente necessária (e, portanto, uma legítima restrição de liberdade do potencial poluidor), ou não" (MACHADO, 2015, p. 95). Trata-se de um instrumento capaz de combater os riscos decorrentes das falhas científicas, e principalmente a possibilidade de combater as práticas que não possíveis ainda de se provar concretamente as relações causais, subsidiadas por hipóteses científicas.

Já na França, o princípio da precaução foi introduzido pela Charte de l'Environnement, que foi promulgada pela Lei Constitucional 2005-205. Trata-se de uma carta com 10 artigos e coloca o meio ambiente na Constituição Francesa, num mesmo patamar de igualdade com a Declaração Universal dos Direitos do Homem e do Cidadão de 1789 e dos Direitos Econômicos e Sociais de 1946.

O princípio da precaução está contido no art. $5^{\circ}$ dessa Carta da seguinte forma:

Quando a ocorrência de um dano, ainda que incerto diante do estado dos conhecimentos científicos, possa afetar de modo grave e irreversível o meio ambiente, as autoridades públicas providenciarão, através da aplicação do princípio da precaução e nas áreas de suas atribuições, a implementação de procedimentos de avaliação de riscos e a adoção de medidas provisórias e proporcionais com a finalidade de evitar a realização de um dano $\left(\right.$ MACHADO, 2015, p. 97) ${ }^{4}$.

Outras políticas encontradas nos Estados Unidos da América (EUA), dentro deste contexto, tentaram mitigar os prejuízos de uma ação danosa como a prudente avoidance - "evitar com prudência" - que foi utilizada nos casos de emissões eletromagnéticas, trata-se de uma política de medidas simples, fáceis de serem executadas e com baixo custo para reduzir a exposição ou ainda pode-se citar a política cautelar conhecida como ALARA (As Low As Reasonsbly Achevable). Porém nenhuma delas elimina completamente o risco, mas apenas tenta minimizar os prejuízos mantendoos de qualquer forma (ÁNGEL YÁGÜEZ, 2008, p. 104-105).

Talvez por isso que nos EUA demorou-se em utilizar o conceito do princípio da precaução e a doutrina jurídica utilizou o termo "abordagem de precaução". E segundo ensinamento de Machado (2015): "o princípio da precaução evoluiu, pelo menos na literatura jurídica, de uma ferramenta

\footnotetext{
${ }^{4}$ Tradução do professor Machado (2015) do: "Article 5. Lorsquelaréalisation d'undommage, bienqu'incertaineenl'étatdesconnaissancesscientifiques, pourraitaffecter de manière grave et irréversiblel'environnement, lesautorités publiques veillent, par applicationduprincipe de précaution et dansleursdomaines d'attributions, à lamiseenoeuvre de procédures d'évaluationdes risques et à l'adoption de mesures provisoires et proportionnéesafin de parer à laréalisationdudommage" (FRANÇA, 2005).
} 
limitada para preencher a lacuna entre a atual informação da sociedade, que deseja limitar a exposição aos riscos sérios, para uma regra mais difícil" (MACHADO, 2015, p. 98).

Veja-se que o princípio da precaução é usado como uma ferramenta para prevenir danos à saúde e ao meio ambiente, já que particularmente naquele país o princípio da precaução aflora nos ordenamentos relativos às substâncias tóxicas ou persistentes ou bioacumuláveis.

É importante ressaltar que o princípio da precaução é usado para preencher as lacunas existentes entre a exposição de riscos latentes da sociedade com o atual estado dos conhecimentos científicos disponíveis. Não que seja uma tarefa fácil, mas que dependerá de um amplo aprofundamento das questões envolvidas tanto para se determinar aquilo que pode ser afirmado, quanto as incertezas da própria ciência.

Há um consenso nos países acima mencionados que o princípio da precaução está fundamentado nos avanços da ciência, por meio dele, pode-se promover alterações sobre os atuais padrões de proteção ao meio ambiente, sendo importantíssimo que as razões que fundamentem as incertezas científicas sejam plenamente divulgadas.

\subsection{Da incerteza científica}

Ainda quanto ao direito estrangeiro, mas com enfoque sobre a incerteza científica, convém expor sobre os postulados do documento COM (2000) 1, cujo princípio da precaução justifica-se:

[...] quando a preliminar e objetiva avaliação científica indica que existem motivos razoáveis para temer efeitos potenciais perigosos que possam ser incompatíveis com o nível de proteção escolhido pela própria Comunidade europeia. Isto é dito no número 3 do resumo, que abre o documento.

Ademais, no número 4 do mesmo resumo lê-se: O recurso ao princípio de precaução pressupõe que se identificaram os efeitos potencialmente perigosos, derivados de um fenômeno, um produto ou um processo, e que a avaliação científica não permite determinar o risco com suficiente certeza (ÁNGEL YÁGÜEZ, 2008, p. 105).

Importante ressaltar que a avaliação científica se encontra no centro desta discussão, tanto para usar ou não o princípio da precaução.

Por outro lado, convém destacar a advertência feita por Ángel Yágüez (2008), que ao tratar sobre o método científico, explica que não se permite estabelecer a ausência de um efeito, ou seja, não se refere ao fato que certeza absoluta não existe.

Exemplifica sua explicação da seguinte forma:

Por socorrer a um exemplo imaginário, a ciência poderia provar que o café tem efeitos cancerígenos, mas nunca poderá comprovar que não os tem. [...]

Ah! Por certo o exemplo do café não é tão imaginário como se dizia, posto que na classificação da Agencia Internacional para pesquisa do Câncer, de Lyon (IARC), arrola-se o café, junto com outros produtos (por exemplo, a sacarina ou a gasolina) ou alguns trabalhos (em carpintaria, funilarias e indústrias têxteis), dentro do chamado "Grupo 2B", que se refere a agentes possivelmente cancerígenos (ÁNGEL YÁGÜEZ, 2008, p. 109 e 110). 
Segundo Ángel Yágüez (2008), os destinatários do princípio da precaução são os responsáveis políticos. Em resumo, a expressão princípio da precaução seria própria da linguagem política e não jurídica, porque constitui uma medida que pode ser adotada na valoração dos riscos, portanto seria de cunho político (ÁNGEL YÁGÜEZ, 2008, p. 101-103).

Por isso, para Ángel Yágüez (2008), hoje o que se deveria buscar delimitar é o que não está delimitado pelo atual estado da ciência.

Se o conhecimento científico sofre influência direta das instituições em que é gerado, há pouca possibilidade de uma concepção neoliberal numa sociedade pós-moderna se sujeitar a limites de uma vontade política que lhe é posta a serviço.

Neste contexto, a instituições tem a missão de espalhar o desconhecimento, a ignorância, o conhecimento equivocado (consciente ou inconsciente), seu objetivo seria colocar pensamentos falsos e ilusórios nas mentes humanas, porque o ser humano não poderia ter um conhecimento verdadeiro dos fenômenos psíquicos, políticos, econômicos ou sociais, mas apenas um conhecimento aproximado, deformado, equivocado. Esse "desconhecimento" se coloca como elemento estrutural da vida social. A função do desconhecimento é tornar o mundo mais seguro para responder aos diversos problemas enfrentados pelas pessoas, em conformidade com Enriquez (2001). Dessa forma:

A sociedade, agregação ou conglomerado de diversas instituições edificadas há muito tempo ou recentemente, impõe suas visões e diretrizes (suas obrigações, diria Durkheim) aos seus membros. Ela se quer admirada e venerada como qualquer sistema de poder. Ela se apropria, frequentemente, das necessidades, das vestes do Estado, da pátria, da nação. E, como instância transcendente, recusa a contestação, em nome da defesa do bem comum. (ENRIQUEZ, 2001, p. 52)

A instituição define quem tem o direito à palavra, o que se pode dizer e principalmente o que não se pode dizer. Enfim, define como se dizer, no intuito de reafirmar ser poder e combater qualquer ameaça, sem se importar na verdade contida de seu discurso.

Nesta vereda, Foucault (1979) delineia a genealogia dos saberes, que não seria um retorno positivista de uma forma de ciência, mas uma anti-ciência. "Trata-se de uma insurreição dos saberes não tanto contra os conteúdos, os métodos e os conceitos de uma ciência, mas de uma insurreição dos saberes antes de tudo contra os efeitos de poder centralizadores ligados à instituição" (FOUCAULT, 1979, p.97). Desta maneira, o que se busca combater são as superioridades impostas ao discurso tido como científico organizado, pouco importando que seja realizado em uma universidade ou no aparelho político. A genealogia seria uma tentativa de libertar da sujeição os saberes históricos e colocá-los em condições de oposição ao discurso teórico, unitário, formal e científico.

A busca por uma sociedade mais sustentável deve ter instrumentos capazes de propor uma prática em que prevaleça a justiça social. A complexidade ambiental na qual se está inserida deve levar em consideração a assimilação do saber ambiental (mais amplo, holístico, atento às outras realidades) dentro dos paradigmas socioambientais legitimados como forma conter o simples avanço capitalista/consumista. 


\section{PRINCÍPIO DA PRECAUÇÃO NO DIREITO BRASILEIRO}

No direito brasileiro, o princípio da precaução também seria um norte para a atuação do administrador público ou para o tomador de decisões. "A Administração Pública direta e indireta de qualquer dos poderes da União, dos Estados, do Distrito Federal e dos Municípios obedecerá aos princípios de legalidade, impessoalidade, moralidade, publicidade e eficiência [...]" (BRASIL, 1988), de acordo com o art. 37 da CR/1988. Porém, não poderá a Administração Pública agir arbitrariamente em suas tomadas de decisão, porque o art. 225 da CR/1988 impõe ao Poder Público o dever de defesa e conservação do meio ambiente e da sadia qualidade de vida para as presentes e futuras gerações.

Não é por menos que Wedy (2009) ensina:

Com efeito, o estado viola o princípio constitucional da moralidade e da legalidade quando não adotar medidas de precaução. Não há nesse ponto como o Estado agir discricionariamente: havendo risco de dano e incerteza científica, o princípio da precaução deve ser aplicado, sob pena de responsabilização estatal no caso da ocorrência de danos ao meio ambiente (WEDY, 2009, p. 137)

Para dispensar este dever de defesa e conservação, a Administração Pública deve fundamentar exaustivamente seus motivos, considerando a relevância do impacto ambiental diante do benefício para sociedade em consonância aos deveres acima expostos.

Porém o princípio da precaução seria uma regra de direito, porque o Princípio 15 da Declaração do Rio (Eco 92) consagrou o princípio da precaução:

Com o fim de proteger o meio ambiente, o princípio da precaução deverá ser amplamente observado pelos Estados, de acordo com suas capacidades. Quando houver ameaça de danos graves ou irreversíveis, a ausência de certeza científica absoluta não será utilizada como razão para o adiamento de medidas economicamente viáveis para prevenir a degradação ambiental. (ONU, 1992, internet)

Neste sentido, ensina o Machado (2015) sobre a inclusão do princípio da precaução no direito brasileiro, através de duas convenções: "Duas convenções internacionais assinadas, ratificadas e promulgadas pelo Brasil inseriam o ‘princípio da precaução”' (MACHADO, 2015, p. 90).

A primeira se refere à convenção da Diversidade Biológica, Assinada no Rio de Janeiro em 5 de junho de 1992 - ratificada pelo Congresso Nacional por meio do Decreto Legislativo no 2/1994, tendo entrado em vigor para o Brasil em 29 de maio de 1994 e promulgado pelo Decreto no 2.519/1998 -, que dispõe em seu preâmbulo: "Observando também que, quando exista ameaça de sensível redução ou perda de diversidade biológica, a falta de plena certeza científica não deve ser usada como razão para postergar medidas para evitar ou minimizar essa ameaça [...]" (BRASIL, 1994). A segunda refere-se à Convenção-Quadro das Nações Unidas sobre Mudança do Clima, assinada em Nova York, em 9 de maio de 1992 - ratificada pelo Congresso Nacional pelo Decreto 
Legislativo no 1/1994, tendo entrado em vigor para o Brasil em 02 de julho de 1998 e promulgado pelo Decreto no 2.652/1998. Assim dispõe em seu art. $3^{\circ}$ :

\title{
Artigo 3.
}

Princípios

$[\ldots]$

3. As Partes devem adotar medidas de precaução para prever, evitar ou minimizar as causas da mudança do clima e mitigar seus efeitos negativos. Quando surgirem ameaças de danos sérios ou irreversíveis, a falta de plena certeza científica não deve ser usada como razão para postergar essas medidas, levando em conta que as políticas e medidas adotadas para enfrentar a mudança do clima devem ser eficazes em função dos custos, de modo a assegurar benefícios mundiais ao menor custo possível. Para esse fim, essas políticas e medidas-devem levar em conta os diferentes contextos sócioeconômicos, ser abrangentes, cobrir todas as fontes, sumidouros e reservatórios significativos de gases de efeito estufa e adaptações, e abranger todos os setores econômicos. As Partes interessadas podem realizar esforços, em cooperação, para enfrentar a mudança do clima (BRASIL, 1998).

Ainda para corroborar com já explanado, convém ressaltar que o princípio da precaução está contido no art. 225 da CR/1988, por isso concluem Costa e Moreira (2014):

O art. 225 da Constituição da República Federativa do Brasil de 1988 impõe ao Poder Público e à coletividade o dever de preservar o meio ambiente e esse é um dos pilares da proteção ambiental, uma vez que implica na formação de uma espécie de pacto atual e intergeracional, mediante a atribuição de responsabilidades por danos causados ou simplesmente possíveis prevenção ainda que improváveis precaução, restrições ao uso dos bens ambientais e competências em matéria de gestão ambiental Poder Público (COSTA; MOREIRA, 2014, p. 111).

Em seguida afirmam também que:

\begin{abstract}
Esse pacto de solidariedade legitima a criação de mecanismos internos de precaução, prevenção* e repressão a danos ambientais, entre os quais se destacam as normas relativas à compensação ambiental, importante ferramenta na proteção da biodiversidade e equilíbrio dos ecossistemas, que é objeto do presente estudo (COSTA; MOREIRA, 2014, p. 112).
\end{abstract}

Segundo ensinamento de Machado (2015):

Há riscos inaceitáveis, como aquele que coloca em perigo os valores constitucionais protegidos, como o meio ambiente ecologicamente 
equilibrado, os processos ecológicos essenciais, o manejo ecológico das espécies e ecossistemas, a diversidade e a integridade do patrimônio biológico - incluído o genético - e a função ecológica da fauna e flora. Repita-se que o princípio da precaução é uma ferramenta para evitar o dano ambiental e implementar o direito de todos ao meio ambiente equilibrado e à sadia qualidade de vida (MACHADO, 2015, p. 101).

Nesse contexto, o princípio da precaução se torna um antídoto aos riscos, como explicitado no relatório do voto do Ministro Humberto Martins, proferido no Recurso Especial no 1.285.463/SP 2011/0190433-2, publicado em 06 de março de 2012 - enquanto relator na Segunda Turma, no qual cita a doutrina de Treich e Gremaq, dispondo da seguinte forma:

[...] no mundo da precaução há uma dupla fonte de incerteza: o perigo ele mesmo considerado e a ausência de conhecimentos científicos sobre o perigo. A precaução visa justamente a gerir a espera da informação. Ela nasce da diferença temporal entre a necessidade imediata de ação e o momento onde nossos conhecimentos científicos vão modificar-se (RECURSO ESPECIAL No 1.285.463/SP - 2011/0190433-2, Relator: Ministro Humberto Martins, $2^{\text {a }}$ Turma, publicado em 06/03/2012)

Os riscos que se buscam limitar, são os riscos intoleráveis, posto que causam significativo dano ambiental, comprovada existência de risco ao meio ambiente em todas suas formas (abiótico, biótico ou antrópico).

Por fim, o princípio da precaução, segundo Canotilho e Leite (2008), funciona como uma espécie de princípio "in dúbio pro ambiente", ou seja, no caso de dúvida se a atividade causa dano ao meio ambiente, deve-se decidir à favor da preservação ambiental e contra o potencial poluidor. Acrescenta ainda que "quando ainda não se verificarem quaisquer danos decorrentes de uma determinada actividade, mas se receia, apesar a falta de provas científicas, que possam vir a ocorrer" o princípio da prevenção deve ser aplicado (CANOTILHO; LEITE, 2008, p. 42).

A CR/1988 no art. $225, \S 1^{\circ}$, inciso $\vee$, dispõe:

Art. 225 da CR/1988. Todos têm direito ao meio ambiente ecologicamente equilibrado, bem de uso comum do povo e essencial à sadia qualidade de vida, impondo-se ao Poder Público e à coletividade o dever de defendê-lo e preservá- lo para as presentes e futuras gerações.

$\S 1^{\circ}$ Para assegurar a efetividade desse direito, incumbe ao Poder Público:

[...]

$V$ - controlar a produção, a comercialização e o emprego de técnicas, métodos e substâncias que comportem risco para a vida, a qualidade de vida e o meio ambiente (BRASIL, 1988).

Veja-se que a CR/1988 menciona a existência de risco, mas de outro lado, não define o que seria este risco. 
Diante disto, Machado (2015) ensina que a CR/1988 inclui o princípio do controle de risco, que seria uma maior amplitude ao princípio da precaução, senão veja-se:

Há diferença essencial na amplitude do "princípio da precaução", inscrito no n. 15 da Declaração do Rio de Janeiro/1992, e na dimensão do "princípio do controle do risco", inscrito no art. 225 da CF brasileira. A Declaração mostra o princípio da precaução limitado às ameaças sérias e irreversíveis. $O$ princípio de controle do Poder Público nas atividades mencionadas ocorrerá sempre que houver risco para a vida, risco para a qualidade de vida e risco para o meio ambiente (MACHADO, 2015, p. 100).

Logo em seguida, Machado (2015) conclui esta nova modalidade de princípio, como um desdobramento do princípio da precaução, está baseada na incerteza. Define o risco como "a possibilidade real ou realista de um acontecimento negativo ou um dano decorrente do que não é certo, ou esperado, mas só mais ou menos provável" (MACHADO, 2015, p. 100). E ainda conclui que o princípio da precaução é ferramenta importantíssima na gestão ambiental sustentável: "Repita-se que o princípio da precaução é uma ferramente para evitar o dano ambiental e implantar o direito de todos ao meio ambiente equilibrado e à sadia qualidade de vida" (MACHADO, 2015, p. 101).

Nesta mesma direção, Sampaio (2003) afirma:

Avançando na interpretação dos dois princípios, Chris Wold se posiciona com Cranor, entendendo que "a precaução não se aplica apenas a ações sob condições de incerteza, mas tem implicação inclusive quando a autoridade que irá decidir não se encontra diante de uma considerável dúvida", já que "a complexidade dos ecossistemas sempre introduz algum grau de incerteza, inclusive sobre os danos supostamente conhecidos e previsíveis": WOLD, Chris. Introdução ao estudo dos princípios de direito internacional do meio ambiente (SAMPAIO; WOLD; NARDY, 2003, p. 7172).

A partir dessas premissas, o uso da precaução repelirá todo argumento de dúvida que subsidia a degradação ambiental e em sentido contrário impelirá a adoção de medidas mais eficazes para fortalecimento da proteção ao meio ambiente.

\section{PRINCÍPIO DA PRECAUÇÃO COMO INSTRUMENTO DE GESTÃO}

O princípio da precaução, conforme exposto, pode ser usado como instrumento de gestão e controle dos riscos. Convém ainda ressaltar que o referido princípio se coloca como norma instrutiva para o controle de riscos ambientais.

Segundo Machado (2015, p. 101), o princípio da precaução deve ser usado para controlar os riscos, bem como para se exigir a compensação (MACHADO, 2015, p. 283).

De mesmo modo, Wedy (2009) afirma que o princípio da precaução é um instrumento de tutela do meio ambiente a ser utilizado pelo Estado, estendendo sua esfera de atuação, não apenas no âmbito administrativo ou jurídico, mas também na esfera legislativa: 
O princípio da precaução como instrumento de tutela do meio ambiente deve ser aplicado e implementado pelo Estado de modo a, além de garantir a referida tutela, não causar danos quando da sua aplicação. O Estado, ao praticar atos administrativos, legislativos ou jurisdicionais, não pode aplicar o princípio da precaução de forma excessiva ou inoperante, pois nestes casos poderá causar danos ao meio ambiente que deverão ser reparados (WEDY, 2009, p. 128-129).

Correto enfatizar que a adoção do princípio da precaução na gestão ambiental, pelos órgãos administrativos principalmente, ocorrerá em sua avaliação sobre a viabilidade do licenciamento do empreendimento conquanto seus impactos sobre o meio ambiente.

Neste ato, o órgão ambiental competente deve analisar cautelosamente a atividade poluidora e expor as diretrizes de sua tomada de decisão para concessão ou não do empreendimento.

Caso não seja possível fundamentar corretamente sua tomada de decisão, por falta de dados técnicos ou por falta de conhecimento científico sobre as implicações do produto ou atividade, é necessário o uso do princípio da precaução.

Esse é o entendimento extraído do art. $5^{\circ}$ da Resolução nº 01/1986 do Conselho Nacional do Meio Ambiente (CONAMA), que preconiza o dever de contemplar todas as alternativas tecnológicas e acrescenta ainda a necessidade de confrontar com a hipótese de não execução do projeto. As diretrizes da Resolução nº 01/1986 buscam resguardar a proteção do meio ambiente e não dão margem para se aceitar a degradação ambiental sem a segurança necessária. Segundo Siqueira (2014):

Tais diretrizes visam a prévia identificação de todos os possíveis impactos de empreendimentos ou atividades ao meio ambiente, verificando a sua tolerabilidade e já informando as medidas mitigatórias e compensatórias adequadas, consagrando, assim, o princípio da prevenção. Não se obtendo segurança quanto aos efeitos do empreendimento a ser licenciado, o EIA autorizará a conclusão pela inviabilidade de seu licenciamento, o que implica na materialização do princípio da precaução. Não procede, portanto, a afirmação quanto à incerteza dos impactos ambientais (SIQUEIRA, 2014, p. 209).

E o princípio da precaução é um instrumento que vai além do tema de poluição, porque será aplicado em outros ramos do direito ambiental. Nesse sentido Freston e Hey (2004) expõem sobre a sua aplicação no interessante exemplo da pesca de arrasto:

Dessa forma, o desenvolvimento do pensamento precautório, em relação ao direito internacional da pesca, pode ser utilizado. Ainda que específico, fornece um exemplo interessante da forma como a abordagem precautória, originalmente desenvolvida no contexto do controle da poluição antropogênica, pode ser estendida para uma área totalmente diferente, a de exploração de recursos vivos (FRESTONE; HEY, 2004, p. 219). 
Diante disto, fica claro que o princípio da precaução é um instrumento capaz de ser usado sob diversas formas e sob vários aspectos na proteção ao meio ambiente, devendo ser usado, como tantos outros princípios, de acordo com a razoabilidade e proporcionalidade.

Corrobora com este entendimento Wolfrum (2004), ao esclarecer que:

\begin{abstract}
O princípio da precaução possui várias características substantivas e procedimentais. Estas devem ser consideradas como mecanismos para implementar as primeiras. O princípio da precaução não requer medidas reguladoras particulares; seu interesse está em quando as medidas conservadoras devem ser tomadas. No entanto, ao se fazer assim, muda-se significativamente a abordagem para as atividades com um impacto potencialmente negativo sobre o ambiente. Em vez de esperar até que haja prova de um impacto negativo sobre o ambiente, deve-se agir antes que tal impacto se materialize. Isso requer uma reconsideração de como as decisões políticas relativas ao meio ambiente são tomadas em caso de incerteza científica (WOLFRUM, 2004, p. 15-16).
\end{abstract}

Certo é que o uso do princípio da precaução no controle das atividades potencialmente poluidoras é um instrumento de grande valia para proteção ambiental, e sua negação certamente incorre numa violação não só do ordenamento jurídico pátrio, como uma ofensa direta à proteção do meio ambiente equilibrado para as presentes e futuras gerações.

\title{
6. CONSIDERAÇÕES FINAIS
}

Ao considerar que hoje vive-se em uma sociedade de risco, cada vez mais acostumada com a latência dos riscos de seu modo de vida, pautada na busca constante de um crescimento, primordialmente econômico, verifica-se que se tem caminhado para uma ameaça social, política e econômica.

Não há limites para se atingir as metas e objetivos de constante crescimento, ainda que para isso se imponha um processo de degradação ambiental inevitável.

Muitos dos riscos são assumidos, massificados e colocados perante a sociedade, sendo que parte deles são objetos de restrições do Poder Público, mas por outro lado, alguns riscos sequer são colocados de forma clara à sociedade e nem ao menos são passíveis de comprovação científica. Diante disto surge a necessidade de se refletir sobre como a sociedade está exposta a tantos riscos, dos quais ainda não se pode comprovar sua existência. Mas, certo é que esperar a perfeita comprovação da existência dos riscos cujos contornos a ciência ainda não explica, para somente então se atentar a eles, poderia ser tarde demais.

A complexidade ambiental dos diversos fatores que incidem em sua construção revela a necessidade de antever a existência do risco diante de um possível dano irreparável ao meio ambiente.

Para isso, surge o princípio da precaução, cujo objetivo é evitar que o direito ao desenvolvimento não se sobreponha ao meio ambiente, sem qualquer rédea de contenção, sob 
simples argumento do direito à propriedade e liberdade. A incerteza científica e o risco de dano são os elementos que definem e viabilizam sua implementação.

Assim o princípio da precaução se revelará como um instrumento necessário na gestão socioambiental sustentável, principalmente porque seu objetivo se coaduna com os demais princípios constitucionais, tais como a livre iniciativa, desenvolvimento econômico e propriedade, desde que sejam exercidos de forma harmônica com o dever de proteção do meio ambiente.

Importante também entender que o princípio da precaução como instrumento de gestão deve observar o custo razoável de implementação, ou seja, aplicando-se o princípio da razoabilidade. E, ainda, o princípio da proporcionalidade, ponderando o uso das melhores técnicas disponíveis para o menor impacto ambiental possível, de acordo com o custo-benefício social de uma determinada atividade.

\section{REFERÊNCIAS}

ÁNGEL YÁGÜEZ, Ricardo de. A responsabilidade civil por emissões eletromagnéticas: o "estado da ciência" como solução jurídica. Tradução de Magno Federici Gomes. Brasília: Usina de Letras, 2008.

BECHARA, Erika. Licenciamento e compensação ambiental na Lei do sistema Nacional das Unidades de Conservação (SNUC). São Paulo: Atlas, 2009.

BECK, Ulrich. Sociedade de risco: rumo a uma outra modernidade. 2. ed. Tradução de Sebastião Nascimento. São Paulo: 34, 2011.

BRASIL. Constituição da República Federativa do Brasil de 1988. Diário Oficial da União, Brasília, 05 de outubro de $1988 . \quad$ Disponível em: <http://www.planalto.gov.br/ccivil_03/constituicao/constituicaocompilado.htm>. Acesso em: 14 nov. 2015.

BRASIL. Decreto $\mathrm{n}^{\circ}$ 2.519, de 16 de mar. de 1998. Promulga a Convenção sobre Diversidade Biológica, assinada no Rio de Janeiro, em 05 de junho de 1992. Diário Oficial, Brasília, 17 mar. 1998. Disponível em: <http://www.planalto.gov.br/ccivil_03/decreto/D2519.htm> Acesso em: 02 de dez. 2015.

BRASIL. Decreto $n^{\circ} 2.652$, de $1^{\circ}$ de jul. de 1998. Promulga a Convenção-Quadro das Nações Unidas sobre Mudança do Clima, assinada em Nova York, em 9 de maio de 1992. Diário Oficial, Brasília, 17 mar. 1998. Disponível em: <http://www.planalto.gov.br/ccivil_03/decreto/D2652.htm> Acesso em: 02 de dez. 2015

BRASIL. Superior Tribunal de Justiça. Recurso Especial 1.285.463/SP - 2011/0190433-2. Rel. Min. Humberto Martins - Segunda Turma, Diário de Justiça Eletrônico, Brasília,

06 de mar. de 2012.2 Disponível em: $<$ https://ww2.stj.jus.br/processo/revista/documento/mediado/?componente=ATC\&sequencial=2016059 
3\&num_registro=201101904332\&data=20120306\&tipo=91\&formato=PDF>. Acesso em: 01 de maio de 2015.

CANOTILHO, José Joaquim Gomes; LEITE, José Rubens Morato. Direito constitucional ambiental brasileiro. 2. ed. São Paulo: Saraiva, 2008.

COSTA, Beatriz Souza; MOREIRA, Lilian Maria Ferreira Marotta. A compensação no direito ambiental brasileiro: o caso de Minas Gerais. In: GOMES, Carla Amado. Compensação ecológica, serviços ambientais e protecção da biodiversidade. Lisboa: Instituto de Ciências Jurídico-Políticas, 2014. Cap. 3, p. 110-133.

ENRIQUEZ, Eugène. Instituições, poder e desconhecimento. In: ARAUJO, José Newton Garcia; CARRETEIRO, Teresa Cristina. Cenários sociais e abordagem clínica. São Paulo: Escuta, 2001. p. 49-74.

FIORILLO, Celso Antonio Pacheco. Curso de direito ambiental brasileiro. 13. ed. São Paulo: Saraiva, 2012.

FOUCAULT, Michel. Microfísica do poder. Rio de Janeiro: Edições Graal, 1979. Disponível em: < http://www.nodo50.org/insurgentes/biblioteca/A_Microfisica_do_Poder_-_Michel_Foulcault.pdf>.

Acesso em: 14 jul. 2015.

FRANÇA. Loi constitutionnelle $n^{\circ}$ 2005-205 du 1 mars 2005 relative à La Charte de l'environnement (1). Legifrance. Disponível em: <http://www.legifrance.gouv.fr/ affichTexte.do?cidTexte=JORFTEXT000000790249>. Acesso em: 14 nov. 2015.

FREESTONE, David; HEY, Ellen. Implementando o princípio da precaução: desafios e oportunidades. In: VARELLA, Marcela Dias; PLATIAU, Ana Flávia Barros (Orgs.). Princípio da precaução. Belo Horizonte: Del Rey, 2004. Cap. 8, p. 205-232.

LEFF, Enrique. Aventuras da epistemologia ambiental: da articulação das ciências ao diálogo dos saberes. Tradução de Silvana Cobucci Leite. São Paulo: Cortez, 2012.

LEFF, Enrique. Epistemologia ambiental. 5. ed. Tradução de Sandra Valenzuela. São Paulo: Cortez, 2010.

MACHADO, Paulo Affonso Leme. Direito ambiental brasileiro. 23. ed. São Paulo: Malheiros, 2015.

ORGANIZAÇÕES DAS NAÇÕES UNIDAS. Declaração do Rio sobre meio ambiente e desenvolvimento. Disponível em: <http://www.onu.org.br/rio20/img/2012/01/rio92.pdf>. Acesso em: 02 dez. 2015.

PELLANDA, Patrícia Santos Précoma. A sociedade de risco e o princípio da informação: uma abordagem sobre a segurança alimentar na produção de transgênicos no Brasil. Veredas do Direito, Belo Horizonte, v. 10, n. ${ }^{0}$ 19, p. 89-114, jan./jun. 2013. Disponível em: 
<http://www.domhelder.edu.br/revista/index.php/veredas/article/download/258/341>. Acesso em: 14 nov. 2015.

SALLUM, Alexandre. A primavera silenciosa de Rachel Carson: um país venenoso. 2012. Disponível em: <http://www.revistaecologico.com. br/materia. . php?id=42\&secao=536\&mat=565>. Acesso em: 02 dez. 2015.

SAMPAIO, José Adércio Leite. Constitucionalização dos princípios de direito ambiental. In: SAMPAIO, José Adércio Leite, WOLD, Chris e NARDY, Afrânio. Princípios do direito ambiental: na dimensão internacional e comparada. Belo Horizonte: Del Rey, 2003. p. 45-86.

SIQUEIRA, Lyssandro Norton. Os princípios de direito ambiental e a compensação ambiental no Sistema Nacional de Unidades de Conservação (SNUC). In: GOMES, Carla Amado. Compensação ecológica, serviços ambientais e protecção da biodiversidade. Lisboa: Instituto de Ciências Jurídico-Políticas, 2014. Cap. 5, p. 196-218.

WEDY, Gabriel. O princípio constitucional da precaução: como instrumento de tutela do meio ambiente e da saúde pública. Belo Horizonte: Fórum, 2009.

WOLFRUM, Rüdger. O princípio da precaução. In: VARELLA, Marcela Dias; PLATIAU, Ana Flávia Barros (Orgs.). Princípio da precaução. Belo Horizonte: Del Rey, 2004. Cap. 2, p. 13 -28.

\section{COMO CITAR ESSE DOCUMENTO:}

GOMES, Magno Federici; MESQUITA, Leonardo Paiva de. Sociedade de risco, sustentabilidade para gestão e princípio da precaução. Revista do Direito, Santa Cruz do Sul, v. 3, n. 50, p. 16-33, set. 2016. ISSN 1982-9957.

Disponível

em:

<https://online.unisc.br/seer/index.php/direito/article/view/7863>. Acesso em: doi:http://dx.doi.org/10.17058/rdunisc.v3i50.7863. 